\title{
Pressure and Thrust Measurements of a High-Frequency Pulsed Detonation Tube
}

\author{
N. Nguyen ${ }^{1}$ and A.D. Cutler ${ }^{2}$ \\ The George Washington University, Newport News, VA, 23602
}

\begin{abstract}
This paper describes measurements of a small-scale, high-frequency pulsed detonation tube. The device utilized a mixture of $\mathrm{H}_{2}$ fuel and air, which was injected into the device at frequencies of up to $1200 \mathrm{~Hz}$. Pulsed detonations were demonstrated in an 8-inch long combustion volume, at about $600 \mathrm{~Hz}$, for the quarter wave mode of resonance. The primary objective of this experiment was to measure the generated thrust. A mean value of thrust was measured up to $6.0 \mathrm{lb}$, corresponding to $\mathrm{H}_{2}$ flow based specific impulse of $2970 \mathrm{~s}$. This value is comparable to measurements in $\mathrm{H}_{2}$-fueled pulsed detonation engines (PDEs). The injection and detonation frequency for this new experimental case was much higher than typical PDEs, where frequencies are usually less than $100 \mathrm{~Hz}$. The compact size of the device and high frequency of detonation yields a thrust-per-unit-volume of approximately $2.0 \mathrm{lb} / \mathrm{in}^{3}$, and compares favorably with other experiments, which typically have thrust-per-unitvolume of order $0.01 \mathrm{lb} / \mathrm{in}^{3}$. This much higher volumetric efficiency results in a potentially much more practical device than the typical PDE, for a wide range of potential applications, including high-speed boundary layer separation control, for example in hypersonic engine inlets, and propulsion for small aircraft and missiles.
\end{abstract}

\section{Introduction}

T recent years, many studies have been conducted involving active boundary layer control techniques using pulsed combustion ${ }^{1}$. These techniques work by manipulating the unstable free shear layer, thus exploiting the Coanda-like effect for unsteady reattachment ${ }^{1}$. In high-speed boundary layer control applications, pulsed or synthetic jets require both high impulse and high frequency in order to be effective ${ }^{2}$. Combustion-driven fluidic actuation has the potential to yield a high momentum jet by exploiting the chemical energy of the reactant fuel/air mixture ${ }^{1}$. Because of its potential to yield high impulse at high frequencies, a pulsed detonation tube has potential as an effective flow control device. Another advantage is that it does not have many complex moving parts; therefore it should be more simple and inexpensive to manufacture.

Pulse Detonation Engines, or PDEs, are unsteady propulsion devices that use repetitive detonations to produce a periodic impulse ${ }^{3}$. The PDE differs from conventional propulsion systems in that it relies on detonation rather than deflagration of the fuel/air mixture to produce thrust.

\section{A. Previous Work with PDEs}

Several studies have been conducted for PDEs and pulsejet engines using $\mathrm{H}_{2} /$ air fuel mixtures. Early experiments conducted under J.A. Nicholls, after the end of WWII, focused on the use of intermittent detonation waves as a means of thrust ${ }^{4}$. In these experiments, a detonation tube was suspended using wires so that thrust would cause the tube to swing like a pendulum. Four reactant mixtures were tested: $\mathrm{H}_{2} / \mathrm{O}_{2}, \mathrm{H}_{2} /$ air, acetylene $/ \mathrm{O}_{2}$, and acetylene/air. When the mixture ratio was adjusted correctly, sharp, clear, and even explosions were observed at frequencies up to $35 \mathrm{~Hz}^{4}$. In the end, Nicholls and his team concluded that the intermittent detonation engine had many advantages, including its mechanical simplicity, static thrust capabilities, efficient operation at supersonic velocities, and potential high thrust levels or high fuel economy, but no useful applications were pursued ${ }^{4}$.

More recent investigations of PDEs have been conducted at the Air Force Research Laboratory using aluminum tubes, 2" ID and 36 " in length ${ }^{5}$. Results show that average thrust increased linearly with injection frequency at approximately $0.34 \mathrm{lb} / \mathrm{Hz}$, using stoichiometric pre-mixed $\mathrm{H}_{2} /$ air with a clean air purge fill ratio of $50 \% 5$. In tests with a fill fraction (i.e. the fraction of the tube filled with reactants) of 1.0 at a frequency of $16 \mathrm{~Hz}$, generated thrust

\footnotetext{
${ }^{1}$ Graduate Student, AIAA Student Member.

2 Professor, MAE Dep't, 1 Old Oyster Point Road, Suite 200, AIAA Associate Fellow
} 
measured approximately $5.0 \mathrm{lb}$, and specific impulse was calculated to be approximately $3750 \mathrm{~s}^{5}$. Investigators concluded that PDE performance results are highly scalable to different injection frequencies and tube geometries. Another study conducted at AFRL was aimed at developing an enhanced combustion pulsejet engine (ECPE) for applications at Mach 0 to Mach $3^{6}$. Single shot detonation and cyclic detonation at $100 \mathrm{~Hz}$ pulsejet tube experiments were carried out using a variety of fuel-air mixtures, including $\mathrm{H}_{2} / \mathrm{O}_{2}, \mathrm{H}_{2} /$ air, ethylene/air, and ethylene $/ \mathrm{O}_{2}{ }^{6}$.

Investigations conducted at the General Electric Global Research Center have used ejectors to augment the thrust generated by a 2" ID $\times 36$ " PDE tube burning a stoichiometric hydrogen-air fuel mixture at a frequency of $10 \mathrm{~Hz}^{7}$. General results show that the PDE generated a thrust of $12.9 \mathrm{lb}$, which was augmented $14 \%$ by the presence of an ejector ${ }^{7}$.

A separate study of a $\mathrm{H}_{2}$-fueled high-frequency pulse detonation engine tested a much longer PDE tube geometry, 2.95" ID $\times 86.6$ " long. ${ }^{8}$ Successful tests were achieved at a maximum operating frequency of $32 \mathrm{~Hz}$. In these experiments, the use of Schelkin wire (SW) was used to study its effect on lengthening or shortening the DDT distance in the PDE tube. Two SW lengths were studied, $600 \mathrm{~mm}$ and $1400 \mathrm{~mm}$, and yielded maximum specific impulse of $1800 \mathrm{~s}$ and $2380 \mathrm{~s}$, respectively.

\section{B. Present Work}

The present project is an extension of the work done at NASA Langley by Cutler, et al., in which pulsed combustion of near-stoichiometric $\mathrm{H}_{2} /$ air fuel was observed in chambers of varying size and geometry at various injection frequencies ${ }^{2}$, 9 . As in the previous experiments, time-resolved measurements of pressure at various locations in the combustion volume, pressure, temperature and rate of flow of the reactants, and injection frequency were collected. The major difference between the present test and previous tests is that thrust and specific impulse $\left(\mathrm{I}_{\mathrm{sp}}\right)$ generated by the device is also measured.

\section{Experimental Method}

\section{A. Pulsed Detonation Tube and High-Speed Valve}

A pulsed detonation tube has been designed primarily for flow visualization experiments, although no flow visualizations are described herein. The device is actively fueled with a hydrogen-air reactant mixture through a high-frequency valve. Initially, combustion of the reactant mixture is initiated using a sparkplug. However, after the first cycle, ignition and detonation of reactants occurs by compression due to contact with reactants from the previous cycle and compression by wave propagation. Combustion products are not displaced from the combustion volume by a non-reacting gas in between each reactant injection cycle, as in typical PDEs.

Measurements of time-resolved pressure at various locations in the combustion volume, pressure, temperature and rate of flow of the reactants, and injection frequency were collected. A thrust balance was set-up in the laboratory to measure the thrust generated, and specific impulse was calculated.

Figure 1(a) is a rendering of the device, and Figure 1(b) is a photograph of the mounted assembly ${ }^{10}$. The combustion volume is 8 " in length and has a constant rectangular cross section of 0.5 " $\times 0.75$ ". Windows located along the length of the combustion volume from the base of the combustion volume ( $\mathrm{x}=0$ ") to $\mathrm{x}=6$ " allow for flow visualization within the device, and an additional window is provided at the bottom of the device to allow a laser light sheet to pass through the plane of symmetry. In the present work, these windows were replaced with stainless steel plates. An automobile sparkplug is located at $x=2.75$ " and is fired continuously at $120 \mathrm{~Hz}$, independent of the injection frequency, ensuring that if the combustion in the tube is extinguished it is quickly reignited (conditions permitting). Pressure taps P2, P3, P4, and P4A are located at $\mathrm{x}=0.25$ ”, 4.25”, 7.75", and 7.75", respectively.

The high-speed valve assembly is driven by a motor, which is in turn controlled by the data acquisition program. Figure 2 is a computer rendering of the high-speed valve assembly and rotating shaft. The valve is composed of a rotating shaft supported by high-speed bearings. The shaft rotates in a close-fitted housing with passages for air and $\mathrm{H}_{2} . \mathrm{H}_{2}$ and air pass through the valve through a hole and a slot, respectively. The reactants are combined in a small nozzle before entering the combustion volume at a downward angle of $30^{\circ}$ to the vertical, through a $0.335^{\prime \prime} \times 0.335^{\prime}$ " square nozzle centered at $x=5.42$ ". The shaft is turned by a high-speed motor, capable of up to about $45,000 \mathrm{rpm}$. Valve shaft position was determined using a helium-neon laser aimed at the rotating shaft through the housing assembly of the motor. The laser light is reflected off a reflective spot on the shaft onto a photodiode once per revolution.

Both $\mathrm{H}_{2}$ and air leaked from the valve through the clearance between the valve and housing. This leakage was initially assumed to be small but was subsequently measured to be about $12 \%$ of the $\mathrm{H}_{2}$ and $11 \%$ of the air. Flow rates quoted in this paper are nominal values, measured by the flow meters, and are not corrected for this leakage. 
However, the specific impulse results are calculated using flow rates to the combustor that have been corrected.

\section{B. Thrust Balance Set-up}

In order for a small-scale, high-frequency pulsed detonation tube to be considered for the previously described applications it must be demonstrated that it provides significant thrust. A thrust balance was designed in order to measure the thrust generated by the device. Figure 3 is a simple sketch of the thrust balance used for this experiment ${ }^{10}$. The device is mounted to one end of an aluminum beam, while the other end is loaded with $70 \mathrm{lbs}$. to balance the weight of the device. The center of the beam is attached to a straight rail by means of a pair of linear ball bearings, which act as the fulcrum or pivot point for the system. Additionally, springs in tension are located on either side of the pivot point, connecting the beam to a horizontal support above, to provide a restoring force as the beam is deflected by thrust applied by the device. A linear potentiometer purchased from Celesco Transducer Products, Inc., Model CLWG-150-MC4, is attached to the system to measure displacement in response to thrust.

Calibration was conducted for the thrust balance used in these experiments. The voltage reading across the linear potentiometer needed to be converted to the proportional thrust generated by the device. In order to determine this calibration coefficient, a series of known weights were placed over the exit of the combustion volume, without the presence of any flows, at approximately one-pound increments, and then were removed in the same order. The voltage reading was recorded for each weight placed on or taken off the device. This procedure was conducted several times to ensure repeatability. Uncertainty of the balance measurement is $\pm 7 \%$ due primarily to friction in the potentiometer, and the time for the balance to respond to a change is about $1 \mathrm{sec}^{10}$.

\section{Miscellaneous Instrumentation}

Time-resolved pressure measurements were taken within the combustion chamber at $\mathrm{P} 2, \mathrm{P} 3, \mathrm{P} 4$, and $\mathrm{P} 4 \mathrm{~A}$, as indicated in Figure 1(a). These measurements were taken using 0-200 psi PCB-Piezotronics pressure sensor model 113A21. Pressure taps P2 and P3 have a diameter of 0.076", and two pressure taps of different size are located at the exit, P4 and P4A. The pressure tap on the right, P4, has a diameter of 0.076 ", whereas the one of the left, P4A, has a larger diameter of 0.11". Simultaneous pressure data were collected to compare the time response of these two pressure taps. Preliminary runs with air only at 1704 SLPM were conducted to validate the calibration coefficients for the pressure sensors used in subsequent test runs with and without combustion.

Periodically throughout the testing period the calibration of the pressure sensors was checked, and the calibrations adjusted if required to accommodate any changes that may have occurred due to the extreme conditions to which the sensors were exposed (i.e. high heat, strong vibrations). Although calibration coefficients did change, the difference was small, no larger than $9.5 \%$ in extreme cases, but usually around $\pm 3 \%{ }^{10}$. Another problem that was encountered with the pressure sensors is that they would sometimes fail during testing. Often, the sensor in a given tap would need to be switched with a different sensor, and the case would have to be repeated. Sensor failure usually occurred at high reactant flow rates, where vibration and heat loading was the most extreme.

Simultaneous pressure data with two reactant flow rates - a low flow rate of $852 \mathrm{SLPM} / \mathrm{air}-341 \mathrm{SLPM} / \mathrm{H}_{2}$ and a high flow rate of $1704 \mathrm{SLPM} /$ air-682 SLPM/ $\mathrm{H}_{2}$ - at four fixed frequencies - 235, 300, 475, and $600 \mathrm{~Hz}-$ were collected to compare the time response of the two pressure taps located at the exit, P4 and P4A. These test runs lasted only one second, with a rate of 250,000 samples per second, to allow for better resolution of the pressure data collected. The root mean square pressure for the P4A was found to be approximately 19\% (approximately $1 \mathrm{psi}$ ) greater than that of $\mathrm{P}^{10}$. It is important to note that gauges installed in the $\mathrm{P} 4 \mathrm{~A}$ location did not fare too well in experimental runs due to high heating. If this were not the case, then all pressure taps would have been made the same size.

The spark, which is fired continuously at $120 \mathrm{~Hz}$ during combustion, does not have much effect on the combustion process beyond igniting combustion at the beginning of the run (or reigniting if combustion fails for some reason). Although spark firing does not have an effect on the detonation cycle, combustion appeared to have an effect on spark firing. A likely explanation for this behavior is that the combustion products have a much lower voltage threshold for arcing than the reactants or regular laboratory air. This lower voltage threshold causes arcing many times in one cycle of the spark generator when combustion products are present, which occurs at peaks in the pressure data.

Pressurized air, $\mathrm{O}_{2}$, and gaseous $\mathrm{H}_{2}$ fuel were supplied to the combustor through the valve, as stated previously. Flow of $\mathrm{H}_{2}$ was measured using a 0-1000 standard liter per minute (SLPM) Hastings mass flow meter, and flow of air was measured using a 0-2500 SLPM Hastings mass flow meter manufactured by Teledyne Hastings Instruments. In runs where $\mathrm{O}_{2}$-enriched air was used, flow of $\mathrm{O}_{2}$ was measured using a 0-300 SLPM Hastings mass flow meter. Uncertainties in flow rates (after correcting for leakage) were approximately $\pm 4 \%$, including uncertainty in leakage flow. Pressure taps were provided in the valve to monitor the mean pressures of the supply $\mathrm{H}_{2}$ and air. Pressure was 
measured with strain gauge type transducers with uncertainty $\pm 1 \%$.

Mean pressures of the supply flows were rather high; for example, at a fuel flow rate of 1704 SLPM/air - 682 $\mathrm{SLPM} / \mathrm{H}_{2}$, mean pressures of the supply flows of air and hydrogen were observed at approximately 130 and $120 \mathrm{psi}$, respectively ${ }^{10}$. This high pressure is necessary to inject the reactant flow through the small orifices of the high-speed valve. The high-speed valve used in the present experiment was not developed to minimize pressure losses. In practical applications, a pulsed detonation device would have a valve optimized to minimize pressure losses (i.e., larger valve minimum areas), and, as a result, would be able to operate at lower supply pressures. However, a device such as the one presented here will always have a significant pressure drop in the injection of reactants because reactant flow is injected at a significant velocity. This is contrasted against a conventional PDE, where in principle the injection velocities are smaller, and the valve could be designed with lower pressure drops.

Figure 4 is a simple schematic of the data acquisition system as it is set up in the laboratory. On a typical run, the LabVIEW program developed for this experiment is initiated on the PC. A/D trigger settings, scope channel settings, and voltage input settings are specified to the program. Once specified reactant flow rates are established and combustion occurs, data acquisition is initiated. Data is collected for a specified amount of time (e.g., 5 seconds), after which it is downloaded to the PC. While data are being downloaded to the PC, the motor is returned to a low frequency, and any excess $\mathrm{H}_{2}$ gas is purged from the laboratory area.

\section{Data Reduction and Analysis,}

Data from the digital oscilloscope contained data points from 4 channels with 250,000 samples per channel, collected over 5 seconds: Channel 1 from the valve shaft position photodiode, Channels 2, 3, and 4 from pressure sensors at P2, P3, and P4, respectively. Signals from Channels 2, 3, and 4 were converted from voltage signals to pressure readings in psi. Data was broken into 0.1 second segments of 5000 samples per channel for reduction. A/D data from the SC-2345 contains data for 14 channels at 1000 samples per second per channel, which is broken into 0.1 second segments of 100 samples per channel.

Channel 1 photodiode data, which contains a string of pulses of finite width, was processed using Fast Fourier Transforms (FFT) to obtain valve opening frequency. Pressure data from Channels 2, 3, and 4 were analyzed to obtain two separate results. First, the short time standard deviation of pressure (RMS pressure) for each 0.1 second segment was computed. The second analysis, which required a number of steps, computed the one-cycle-delay correlation coefficient for each segment. This coefficient was obtained by shifting the data segment one reactant injection cycle and then computing the correlation between the original unshifted and the shifted segment. When the correlation coefficient is one, this indicates perfectly periodic behavior at the injection frequency, when it is zero it indicates uncorrelated behavior. Results for each segment of the data from Channels 2, 3, and 4 could be crossplotted with the valve frequency obtained from Channel 1 data or with time into the test.

\section{E. Test Conditions}

Several types of experimental runs were conducted for the present project. The first set of runs was done to measure pressure at the three locations in the combustion volume at various reactant flow rates, scanning a number of injection frequencies for five seconds. The second set of tests consisted of 10 -second runs to measure the thrust generated at various reactant flow rates and frequencies. Other types of tests included examining the role of spark firing during combustion. For these experiments, reactant flow rates studied include:

- air only (no combustion) - 426, 852, 1278, and 1704 SLPM/air

- a near-stoichiometric mixture of air and $\mathrm{H}_{2}-426,852,1278,1704$, and $2130 \mathrm{SLPM} /$ air with 170,341 , 511,682 , and $852 \mathrm{SLPM} / \mathrm{H}_{2}$, respectively

- $\mathrm{O}_{2}$-enriched air and $\mathrm{H}_{2}$

- several fuel-lean conditions, in which air flow rate was kept constant, but $\mathrm{H}_{2}$ flow rate was decreased.

The near-stoichiometric mixture of air and $\mathrm{H}_{2}$ has an actual equivalence ratio of approximately 0.95 . For the remainder of this discussion, tests conducted and results derived from using the near-stoichiometric mixture will be referred to as "stoichiometric".

Unless otherwise stated, results presented in this paper are derived from data collected at the reference case of $1704 \mathrm{SLPM} / \mathrm{air}-682 \mathrm{SLPM} / \mathrm{H}_{2}$.

\section{Experimental Results}

\section{A. Pressure Time History Results}


Pressure time history data were reduced to obtain RMS pressure (in psi) and one-cycle-delay correlation coefficient as a function of injection frequency. Figure 5 shows results derived from pressure time history results for experiments when combustion occurs with a near-stoichiometric fuel-air mixture at the reference flow rate. Comparison of results from cases with air only to cases with combustion shows that RMS pressure increases significantly as a result of combustion, which is to be expected.

Another effect of combustion is that the $\lambda / 4$ mode resonant frequency has increased from about $400 \mathrm{~Hz}$ to about $600 \mathrm{~Hz}^{10}$. Resonance is identified as a frequency at which the pressure fluctuations peak and the waveform is periodic; the mode of resonance is identified by inspection of the amplitude and relative phases of waveform at the different pressure taps. The quarter wave $(\lambda / 4)$ mode of resonance is where the pressure fluctuation amplitude is greatest at the closed end of the tube and zero at the exit, and the fluctuations at various pressure taps are in phase. Increase in experimentally determined resonant frequency is consistent with previous work ${ }^{2}$, in which the resonant frequency was found to increase less than expected based on the higher speed of sound in the combustion products. The speed of sound in combustion products is $3200 \mathrm{ft} / \mathrm{s}$, compared to $1130 \mathrm{ft} / \mathrm{s}$ in air. Using this new speed of sound, the theoretical resonant frequency is calculated to be $1200 \mathrm{~Hz}$, which is double the experimentally obtained resonant frequency of $600 \mathrm{~Hz}$. This discrepancy must be due in part to the presence of unburned reactants with lower speed of sound in the tube during much of the detonation cycle. Another cause may come from the combination of several non-linear processes occurring during detonation (i.e., formation of the shock, heat addition, combustion process, chemistry of the reactants). The present work does not include results for injection of reactants at a frequency of $1200 \mathrm{~Hz}$; therefore, it cannot be said that resonance does not occur at this injection frequency. Previous work has shown that waveforms are chaotic at around $999 \mathrm{~Hz}$ but periodic again at about $1401 \mathrm{~Hz}^{2}$; however, waveforms of these higher frequency resonances are not consistent with the $\lambda / 4$ mode, but instead with another higher frequency mode, and detonations did not occur.

Figure 6 shows segments of pressure time history for the reference flow rate at two injection frequencies, about $300 \mathrm{~Hz}$ and $600 \mathrm{~Hz}$. Valve opening, shown in red, is plotted with pressure traces collected from Channels 2, 3, and 4. During the up- and down-slope of the valve opening trace, only a fraction of the flow passages in the rotating shaft of the high-speed valve are open to the corresponding passages in the valve housing assembly. At the peak of the valve opening trace, passages are perfectly aligned, allowing for maximum injection of reactants. Figure 6 shows that detonations occur at almost every injection cycle, i.e., with each valve opening. The pressure plots for each gauge are offset vertically from each other in order to observe each individually. Therefore, only the relative values indicated on the plot are significant. The pressure amplitude is defined as the difference between minimum and peak values in a cycle.

There exists a bias error in the pressure measurements due to the small size of the pressure taps. This bias error results in the pressure amplitude of detonations being measured roughly $63 \%$ of their true value. Thus, true amplitudes of the pressure fluctuations are likely over 200 psia. The C-J prediction for detonations of stoichiometric $\mathrm{H}_{2}$ and air at $1 \mathrm{~atm}$ is $168 \mathrm{psia}^{2}$. However, in reality the pressure in the combustion tube is oscillating around atmospheric pressure, and at the moment of detonation is higher than 14.7 psia. Since the C-J pressure just after detonation is expected to roughly scale with the pressure just prior to it, the pressure after detonation is expected to be greater than 168 psia. Although there are large uncertainties, it appears that the actual pressure amplitudes in the combustion tube are roughly consistent with C-J detonations.

Figure 5(b) is a plot of one-cycle-delay correlation coefficient for combustion in the detonation tube. At about $300 \mathrm{~Hz}$, amplitude and shape of each pressure fluctuation are not very consistent, which is why the correlation coefficient is not very close to one. At about $600 \mathrm{~Hz}$, the pressure fluctuations are more consistent from one cycle to the next, which corresponds to a local peak in the correlation coefficient. Consider Figure 6 at $600 \mathrm{~Hz}$, which shows strong, periodic detonations occurring at the resonant frequency. Amplitude of the pressure fluctuation is three times that with air only (and, in reality, probably more given the bias error in the gauges). Also, detonations occur at the peak in pressure of the underlying $\lambda / 4$ mode, unlike at half the resonant frequency of $300 \mathrm{~Hz}$, where detonations occur just after the peak, causing a small "hump" in the waveform just before the detonation.

\section{B. Thrust Balance Results}

Thrust balance measurements were acquired at various reactant flow rates and injection frequencies. Results showed that thrust is generally a maximum at the resonant frequency, about $600 \mathrm{~Hz}$, except at the highest flow rate of $2130 \mathrm{SLPM} /$ air-852 SLPM/ $\mathrm{H}_{2}$. At this flow rate, maximum thrust of $6.27 \mathrm{lb}$. occurs at around $525 \mathrm{~Hz}$, but it is not significantly higher (only $+3.64 \%$ ) than the thrust measured at approximately $600 \mathrm{~Hz}$, which is $6.05 \mathrm{lb}^{10}$.

Figure 7 is a plot of time averaged specific impulse, $I_{\mathrm{sp}}$, for various frequencies at a number of nearstoichiometric reactant flow rates. At the resonant frequency of $600 \mathrm{~Hz}$, the $\mathrm{I}_{\mathrm{sp}}$ of the three highest flow rates is approximately $2800 \mathrm{~s}^{10}$. The close similarity between the three highest flow rates indicates that combustion is 
complete at these flow rates and frequencies. At the lower flow rates, low $\mathrm{I}_{\mathrm{sp}}$ is a result of incomplete combustion in the tube.

\section{Miscellaneous Results}

Tests were also conducted replacing $10 \%$ of the air flow with $\mathrm{O}_{2}$, with the flow rates otherwise kept the same as the cases with a near-stoichiometric mixture of air and $\mathrm{H}_{2}$. The $\mathrm{O}_{2}$-enriched cases were conducted to determine if combustion is complete in the device, and to determine if the performance is limited by reaction rate. In the nearstoichiometric case, there is exactly enough $\mathrm{O}_{2}$ present in the air to completely consume the $\mathrm{H}_{2}$, assuming that $\mathrm{H}_{2}$ and air mix perfectly; however, the addition of $\mathrm{O}_{2}$ to the airflow may help the $\mathrm{H}_{2}$ to be consumed more completely in cases where $\mathrm{H}_{2}$ and air do not mix perfectly. Results with $\mathrm{O}_{2}$-enriched air and $\mathrm{H}_{2}$ were compared to the nearstoichiometric cases. If $\mathrm{H}_{2}$ and air mix perfectly, and all the $\mathrm{H}_{2}$ reacts, then the cases with added $\mathrm{O}_{2}$ should yield the same heat release, thrust, and RMS pressure. Increase in RMS pressure in cases with added $\mathrm{O}_{2}$ would indicate that the $\mathrm{H}_{2}$ was not all reacted for cases without $\mathrm{O}_{2}$ addition, and is now reacting more completely. If the differences between the near-stoichiometric mixture and the $\mathrm{O}_{2}$-enriched mixture are small, then it can be assumed that the reaction of $\mathrm{H}_{2}$ is complete without the additional $\mathrm{O}_{2}$. Another effect of $\mathrm{O}_{2}$ addition is to increase the rate of reaction.

At lower flow rates, introduction of $\mathrm{O}_{2}$ into the reactant mixture increased RMS pressure fluctuations from gauge P2 by about $40 \%$ at lower injection frequencies and about $25 \%$ at higher injection frequencies. Similarly, P3 RMS pressure fluctuations increased approximately $20 \%$ at lower injection frequencies, but no significant changes are noticed at high frequencies or in P4 RMS pressure fluctuations ${ }^{10}$. This increase in RMS pressure reaffirms the fact that reaction was not complete at this low flow rate without the addition of $\mathrm{O}_{2}$. For the higher flow rate, the addition of $\mathrm{O}_{2}$ in the reactant mixture does not significantly change the RMS pressure for any of the gauges. This indicates that mixing and combustion of the reactant mixture was complete without the addition of $\mathrm{O}_{2}$. Also, RMS pressure fluctuations for the $\mathrm{O}_{2}$-enriched cases appear to peak at similar injection frequencies as the normal combustion cases, indicating that there is no change in the resonant frequency when $\mathrm{O}_{2}$ is introduced into the reactant mixture.

Two fuel-lean cases were chosen for continued testing to compare to a case with a near-stoichiometric mixture of air and $\mathrm{H}_{2}$ at the highest flow rate (2130 SLPM/air - $852 \mathrm{SLPM} / \mathrm{H}_{2}$ ). Detonations continued to occur at the resonant frequency of around $600 \mathrm{~Hz}$; however, this injection frequency did not yield maximum thrust or $\mathrm{I}_{\mathrm{sp}}$, as it did in the near-stoichiometric cases. Figure 8 is a plot of the $I_{s p}$ calculated from steady-state thrust at various injection frequencies for three reactant flow rates: a near-stoichiometric reactant mixture of air and $\mathrm{H}_{2}$ at the highest flow rate and two fuel-lean mixtures of $2130 \mathrm{SLPM} /$ air-739 SLPM/H $\mathrm{H}_{2}$ (fuel lean case 1) and $2130 \mathrm{SLPM} /$ air-682 SLPM/H 2 (fuel lean case 2). Thrust generated at the fuel-lean conditions ranged between 4.5 and $6.0 \mathrm{lb}$. A maximum $\mathrm{I}_{\mathrm{sp}}$ of $3400 \mathrm{~s}$ was calculated for fuel lean case 2 at an injection frequency of about $425 \mathrm{~Hz}^{10}$.

Specific impulse differs greatly at the lower injection frequencies, which is a result of the inconsistent behavior of the thrust generated. However, at around $600 \mathrm{~Hz}$, the $\mathrm{I}_{\mathrm{sp}}$ of the two fuel-lean cases shown is approximately 2700 $\mathrm{s}$, which is similar to the three highest near-stoichiometric flow rates plotted in Figure $7^{10}$. The explanation for this trend is not known. It is possible that there are two offsetting trends whose effect depends on frequency. On the one hand, a fuel-lean condition tends to reduce the reactivity of the reactants, which would be expected to reduce $\mathrm{I}_{\mathrm{sp}}$. On the other hand, fuel-lean increases the mass of the reactants per unit mass of fuel $\left(\mathrm{H}_{2}\right)$, similar to reducing the fill fraction, which in PDEs increases $\mathrm{I}_{\mathrm{sp}}{ }^{5}$ Further studies will need to be conducted in order to clearly understand the effects of operating fuel-lean.

\section{Discussion and Comparison to Literature}

Table 1 summarizes the results of thrust balance tests presented. Maximum thrust and $\mathrm{I}_{\mathrm{sp}}$ are tabulated for each reactant flow rate along with corresponding injection frequency at which the maximum occurs. The last column in Table 1 is the percent difference in $\mathrm{I}_{\mathrm{sp}}$ for each case, using the reference flow rate at around $600 \mathrm{~Hz}$ as the point of comparison. This result was chosen to be the reference $\mathrm{I}_{\mathrm{sp}}$ because it was the case with a near-stoichiometric reactant mixture that produced the best results. 
Table 1 Summary of performance at $600 \mathrm{~Hz}$ injection frequency with various reactant flow rates ${ }^{10}$. The low $I_{\text {sp }}$ value at the two lowest reactant flow rates yield a large percent difference to the reference case. This is

\begin{tabular}{|l|l|l|l|l|l|}
\hline $\begin{array}{l}\text { Nominal flow } \\
\text { rate of Air, } \\
\text { SLPM }\end{array}$ & $\begin{array}{l}\text { Nominal flow } \\
\text { rate of } \mathbf{H}_{\mathbf{2}}, \\
\text { SLPM }\end{array}$ & $\begin{array}{l}\text { Injection } \\
\text { frequency, } \mathbf{H z}\end{array}$ & Thrust, $\mathbf{l b}$ & $\mathbf{I}_{\mathbf{s p}}, \mathbf{s}$ & $\begin{array}{l}\text { Difference } \\
\text { in } \mathbf{I}_{\mathbf{s p}}, \mathbf{\%}\end{array}$ \\
\hline \hline 426 & 170 & 750 & 0.39 & 900 & $-70 \%$ \\
\hline 852 & 341 & 750 & 1.8 & 2100 & $-29 \%$ \\
\hline 1278 & 511 & 600 & 3.7 & 2800 & $-5.7 \%$ \\
\hline $\mathbf{1 7 0 4}$ & $\mathbf{6 8 2}$ & $\mathbf{6 0 0}$ & $\mathbf{5 . 2}$ & $\mathbf{2 9 7 0}$ & -- \\
\hline 2130 & 852 & 525 & 6.3 & 2900 & $-2.4 \%$ \\
\hline 2130 & 682 & 425 & 5.9 & 3400 & $14 \%$ \\
\hline 2130 & 738 & 300 & 5.6 & 2900 & $-2.4 \%$ \\
\hline
\end{tabular}

attributed to incomplete combustion at these low flow rates. At the higher near-stoichiometric flow rates, the percent difference is much smaller. The maximum $\mathrm{I}_{\mathrm{sp}}$ for the fuel lean case 1 had no significant difference from the reference case, whereas maximum $\mathrm{I}_{\mathrm{sp}}$ for fuel lean case 2 had a larger difference of $14 \%{ }^{10}$.

It is useful to compare the thrust balance and $\mathrm{I}_{\mathrm{sp}}$ results from this experiment to those of $\mathrm{H}_{2}$-fueled PDEs from other research facilities. Table 2 lists the results from such experiments. Although the detonation tube discussed here did not produce the largest specific impulse compared to the PDE work, it has larger $\mathrm{I}_{\mathrm{sp}}$ than those of many of the references. Also, the device is much smaller in size than the comparable PDEs. When normalized by combustion tube volume, the detonation tube presented here is far superior to the PDEs considered. The compact size results in a low weight-to-thrust ratio, which is desirable in aircraft and missile applications. It is also important to note that the device presented here operated at much higher injection frequencies than those in the other experiments listed.

Table 2 Summary of results for various experiments ${ }^{10}$.

\begin{tabular}{|c|c|c|c|c|c|c|}
\hline Reference & $\begin{array}{l}\text { Frequency, } \\
\mathrm{Hz}\end{array}$ & $\begin{array}{l}\text { Volume, } \\
V \text { in }^{3}\end{array}$ & $\begin{array}{l}\text { Fill } \\
\text { Fraction }\end{array}$ & $\begin{array}{l}\text { Thrust, T } \\
\text { lb }\end{array}$ & Isp, $\mathbf{s}$ & $T / V, l / \mathbf{i n}^{3}$ \\
\hline Nicholls $^{4}$ & 26.7 & 226 & $<1$ & 3.2 & 2100 & 0.0141 \\
\hline $\operatorname{AFRL}(a)^{5}$ & 16 & 452 & 1 & 6.7 & 3750 & 0.0147 \\
\hline $\operatorname{AFRL~(b)^{5}}$ & 16 & 452 & 0.3 & 3.7 & 7100 & 0.0083 \\
\hline GE-GRC $^{7}$ & 10 & 485 & 1 & 12.9 & 1070 & 0.0266 \\
\hline Zhang $^{8}$ & 32 & 2370 & N/A & -- & $\sim 2000$ & -- \\
\hline Present Work ${ }^{10}$ & 600 & 3 & $1.71^{*}$ & 5.18 & 2970 & 1.73 \\
\hline
\end{tabular}

For the results shown in Table 2 for the present experiment, combustion tube fill fraction is reported as 1.71 for at the reference flow rate at $600 \mathrm{~Hz}$ injection frequency. This value is based on the assumption that the combustion tube pressure is $1 \mathrm{~atm}$ (14.7 psia), and implies that some of the reactants are "spilling" out of the tube during operation $^{10}$. Given that the pressure within the tube when it is filled with reactants is higher than atmospheric, it is likely that the reactants do not in fact significantly spill from the tube.

\section{IV.Conclusions}

Experiments have been conducted to investigate a pulsed detonation tube ${ }^{10}$. The combustion volume was 8 " in length and had a rectangular cross-section of 0.5 " $\times 0.75$ ". A near-stoichiometric mixture of $\mathrm{H}_{2}$ and air was supplied to the tube at various flow rates and at frequencies of up to $1000 \mathrm{~Hz}$. Thrust balance measurements were conducted to determine the thrust and $\mathrm{I}_{\mathrm{sp}}$ generated by the device at different operating conditions.

The major contribution of the present work, as opposed to previous work ${ }^{2}$, is that a thrust balance system was developed and used in order to determine the thrust generated during operation. As expected, detonations in a nearstoichiometric mixture of $\mathrm{H}_{2}$ /air were accomplished in the short $\lambda / 4$ resonant tube, specifically at high reactant flow rates at around $600 \mathrm{~Hz}$ and $300 \mathrm{~Hz}$. Addition of $\mathrm{O}_{2}$ into the reactant mixture helped enhance combustion at lower reactant flow rates. At higher flow rates, mixing and combustion of $\mathrm{H}_{2}$ and air was already complete; therefore, the addition of $\mathrm{O}_{2}$ did not change the behavior of the device.

Maximum thrust attained was approximately $6.0 \mathrm{lb}_{\mathrm{f}}$ at the highest reactant flow rate of 2130 SLPM/air-852 
$\mathrm{SLPM} / \mathrm{H}_{2}$ at the resonant frequency, about $600 \mathrm{~Hz}^{10}$. As expected, thrust increased with reactant flow rate. Specific impulse was consistent for the three highest reactant flow rates at the resonant frequency, with less than a $6 \%$ difference from the reference value of $2970 \mathrm{~s}$ at a nominal flow rate of $1704 \mathrm{SLPM} / \mathrm{air}-682 \mathrm{SLPM} / \mathrm{H}_{2}{ }^{10}$. At the lower flow rates, detonations did not occur at each injection cycle and combustion was not complete, causing low thrust and $\mathrm{I}_{\mathrm{sp}}$.

Fuel-lean conditions were also tested to determine the effect on thrust. Two fuel-lean cases were tested to compare to a case with a near-stoichiometric mixture of air and $\mathrm{H}_{2}$ at the highest flow rate. Detonations continued to occur at the resonant frequency of around $600 \mathrm{~Hz}$; however, this injection frequency did not yield maximum thrust or $\mathrm{I}_{\mathrm{sp}}$, as it did in the stoichiometric cases. Thrust generated at the fuel-lean conditions ranged between 4.5 and 6.0 lb. A maximum $\mathrm{I}_{\mathrm{sp}}$ of $3400 \mathrm{~s}$ was calculated for a reactant mixture of $2130 \mathrm{SLPM} / \mathrm{air}-682 \mathrm{SLPM} / \mathrm{H}_{2}$ at an injection frequency of around $425 \mathrm{~Hz}^{10}$. It is speculated that there are two offsetting trends whose relative importance depends on frequency. First, the reactivity of the reactants would be reduced in fuel-lean cases, and so $\mathrm{I}_{\mathrm{sp}}$ would be expected to decrease. However, fuel-lean conditions are known to increase $\mathrm{I}_{\mathrm{sp}}$. Further studies will need to be conducted in order to clearly understand the effects of operating with fuel-lean conditions.

As stated previously, the combustion volume for this device has a rectangular cross-section, which enables the device to be fitted with windows. Internal flow visualization of the combustion volume was not conducted in the present work, but images of the combustion volume during detonation cycles will lead to a better understanding of the gas dynamics occurring within the device. In future work, flow visualization of the combustion volume and exhaust jet should be conducted. Also, higher frequencies of operation, up to $1400 \mathrm{~Hz}$, should be tested to observe the thrust of the device at higher injection frequencies. As in past studies ${ }^{2,9}$, operation at around $1400 \mathrm{~Hz}$, which corresponds to the $3 \lambda / 4$ waveform, resulted in perfectly periodic deflagration combustion at each injection cycle. This behavior may also be observed in the device if further tests were conducted.

This device was developed primarily as an actuator for flow control. The high specific impulse and high frequencies of operation give it much promise in high-speed boundary layer separation control applications, for example in hypersonic engine inlets. However, possible applications are not limited to flow control. Other applications of a high-frequency PDE include small-scale propulsion applications - such as high-speed munitions, small missiles, supersonic reconnaissance vehicles, and pressure-rise combustors for gas turbine engines. Because of this potential, future research on these applications is encouraged.

\section{Acknowledgments}

The authors would like to thank the engineers and technicians of the Hypersonic Airbreathing Propulsion Branch at the NASA Langley Research Center in Hampton, VA for their assistance, especially J. Phil Drummond, Lloyd Wilson and Aaron Auslender, and the support of NASA under Cooperative Agreement NNL06AA16A.

\section{References}

${ }^{1}$ Crittendon, T, and Glezer, A. "Combustion-Driven Jet Actuators for Flow Control." AIAA-2001-2768, $31^{\text {st }}$ AIAA Fluid Dynamics Conference and Exhibit, Anaheim, CA, 11-14 June 2001.

${ }^{2}$ Cutler, A.D., and Drummond, J.P. "Toward a High-Frequency Pulsed Detonation Actuator." AIAA 2006-555, $44^{\text {th }}$ AIAA Aerospace Sciences Meeting and Exhibit, Reno, NV, 9-12 January 2006.

${ }^{3}$ Ma, F., Choi, J.Y., and Yang, V. "Thrust Chamber Dynamics and Propulsive Performance of Single Tube Pulse Detonation Engines." Journal of Propulsion and Power, Vol.12, No. 3, May - June 2005.

${ }^{4}$ Nicholls, J.A., Wilkinson, H.R., and Morrison, R.B. "Intermittent Detonation as a Thrust Producing Mechanism." Jet Propulsion, Vol. 27, pp. 534-541, 1957.

${ }^{5}$ Schauer, F., Stutrud, J., and Bradley, R. "Detonation Initiation Studies and Performance Results for Pulsed Detonation Engine Applications." AIAA 2001-1129, $39^{\text {th }}$ AIAA Aerospace Sciences Meeting and Exhibit, Reno, NV, 8-11 January, 2001.

${ }^{6}$ McManus, K., Furlong, E., Leyva,I., and Sanderson, S. "MEMS-Based Pulse Detonation Engin for Small-Scale Propulsion Applications." AIAA 2001-3469, $27^{\text {th }}$ AIAA/ASME/SAE/ASEE Joint Propulsion Conference and Exhibit, Salt Lake City, UT, 8-11 July 2001.

${ }^{7}$ Rasheed, A., Tangirala, V.E., Pinard, P.F., and Dean, A.J. "Experimental and Numerical Investigations of Ejectors for PDE Applications." AIAA-2003-4971, $39^{\text {th }}$ AIAA/ASME/SAE/ASEE Joint Propulsion Conference and Exhibit, Huntsville, AL, 21-23 July, 2003.

${ }^{8}$ Zhang, F.Y., Fujiwara, T., Miyasaka, T., Nakayama, E., and Hattori, T. "Detonation Studies of High-FrequencyOperation Pulse Detonation Engine with Air/Hydrogen.” AIAA-2003-1169, 41 ${ }^{\text {st }}$ Aerospace Sciences Meeting and 
Exhibit, Reno, NV, 6-9 January, 2003.

${ }^{9}$ Cutler, A.D., Beck, B.T., Wilkes, J.A., Drummond, J.P., Alderfer, D.W., and Danehy, P.N. "Development of a Pulsed Combustion Actuator for High-Speed Flow Control." AIAA-2005-1084, 43 ${ }^{\text {rd }}$ AIAA Aerospace Sciences Meeting and Exhibit, Reno, NV, 10-13 January 2005.

${ }^{10}$ Nguyen, N.C., and Cutler, A.D. Pressure and Thrust Measurements of a High-Frequency Pulsed-Detonation Actuator, NASA/CR-2008-215315, Hampton, VA, June 2008. 